Société d'histoire de la révolution de 1848 et des

révolutions du XIXe siècle

59 | 2019

Souverainetés africaines

\title{
Ignazio VECA, Il Mito di Pio IX. Storia di un pape \\ liberale e nazionale
}

\section{Arthur Hérisson}

\section{OpenEdition}

\section{Journals}

Édition électronique

URL : https://journals.openedition.org/rh19/6727

ISSN : 1777-5329

Éditeur

La Société de 1848

Édition imprimée

Date de publication : 30 décembre 2019

Pagination : 233-236

ISSN : $1265-1354$

Référence électronique

Arthur Hérisson, "Ignazio VECA, II Mito di Pio IX. Storia di un pape liberale e nazionale ", Revue d'histoire du XIXe siècle [En ligne], 59 | 2019, mis en ligne le 11 janvier 2020, consulté le 07 janvier 2023. URL http://journals.openedition.org/rh19/6727

Ce document a été généré automatiquement le 7 janvier 2023

Tous droits réservés 


\title{
Ignazio VECA, Il Mito di Pio IX. Storia di un pape liberale e nazionale
}

\author{
Arthur Hérisson
}

\section{RÉFÉRENCE}

Ignazio VECA, Il Mito di Pio IX. Storia di un pape liberale e nazionale, Rome, Viella, 2018, 309 p., 29 euros.

1 Issu d'une thèse de doctorat, l'ouvrage d'Ignazio Veca s'inscrit dans une historiographie du lungo Quarantotto soucieuse de réinsérer les événements de 1848 dans le cadre d'une chronologie plus large. Il porte sur un sujet en apparence bien connu mais qui n'avait pourtant jamais été l'objet d'une étude précise: la perception collective de Pie IX comme un pape libéral et national entre son élection sur le trône de Pierre le 16 juin 1846 et les événements de l'année 1849.

Dans le sillage des écrits de Benedetto Croce, l'épisode avait jusqu'à présent été généralement interprété comme une parenthèse dans l'histoire du Risorgimento, fruit d'une illusion éphémère des libéraux italiens. Cette analyse était fondée sur une interprétation téléologique de l'unification italienne, selon laquelle il avait fallu montrer l'aporie des thèses fédéralistes néoguelfes pour que les conceptions unitaires pussent finalement s'imposer. D'après Ignazio Veca, loin d'être une simple illusion, le mythe de Pie IX fut au contraire la conséquence de l'existence au milieu du XIX siècle d'un type de libéralisme et d'un type de catholicisme bien particuliers, que l'ouvrage entend mettre en évidence. La thèse de la parenthèse tendait par ailleurs à réduire l'image du pape à sa seule dimension patriotique. En s'intéressant à des espaces extraitaliens (en premier lieu la France), l'auteur met au contraire en évidence sa dimension internationale et souligne le fait que l'enthousiasme suscité par Pie IX ne fut pas seulement lié à son image de défenseur de l'Italie mais également à celle de promoteur d'une forme de réformisme libéral. 
3 Davantage encore que celui de "mythe ", le concept central de l'ouvrage est celui d'investissement émotif. L'auteur analyse les interprétations de la figure et des actes de Pie IX comme autant d'investissements réalisés par des acteurs divers sur sa personne et sur son rôle. Le concept vise à mettre en avant la diversité des motivations et des stratégies qui conduisirent les contemporains à faire l'éloge du souverain pontife, et par conséquent l'ambiguïté de l'image du pape réformateur, dotée d'une grande plasticité.

4 Le travail est fondé sur des recherches menées dans de nombreux fonds d'archives italiens et français. Il s'appuie par ailleurs sur des sources imprimées de nature variée (pamphlets, tracts, presse périodique, chansons, gravures, etc.). Il faut souligner l'intérêt de son riche carnet iconographique (24 pages), dont les documents sont souvent analysés avec finesse.

5 Les deux premiers chapitres étudient la naissance du mythe de Pie IX et ses fondements. L'auteur met en évidence l'importance de l'amnistie du 17 juillet 1846, adoptée un mois après l'élection du pape et conçue comme un moyen de conquérir la fidélité des indifférents. De cette époque date l'image, ambivalente parce que variant en fonction des préoccupations des acteurs, du pape réformateur susceptible d'apporter à ses sujets un progrès en accord avec les aspirations des sociétés modernes. Pour expliquer l'importance de l'investissement émotif sur le pape, Ignazio Veca met en avant trois facteurs principaux: la mécanique des réformes, les circuits de communication et l'image du pape. À rebours des travaux antérieurs, l'auteur rejette l'idée selon laquelle le rythme irrégulier des réformes aurait été dû aux hésitations d'un pape finalement entraîné par la mobilisation des masses et la pression de l'opinion publique. Il montre que ce rythme fut la conséquence de la logique même du mouvement réformateur, à travers lequel la papauté cherchait à susciter autour d'elle un consensus, en opérant des transformations sur la base d'une mobilisation contrôlée des sujets. Les circuits de communication par lesquels étaient diffusées les nouvelles romaines étaient multiples, mêlant l'ancien et le moderne: rumeurs, gazettes clandestines, opuscules, graffitis sur les murs, correspondances privées, etc. Le gouvernement pontifical encouragea le développement de la presse, pensant qu'elle lui permettrait d'asseoir sa popularité. Celle-ci fut renforcée par la diffusion de l'image du pape, réelle ou reproduite. Dès le début de son pontificat, Pie IX en joua consciemment en multipliant les apparitions publiques. Si les portraits du pape qui circulaient s'inscrivaient dans une tradition ancienne de dévotion religieuse, ils renvoyaient également à des logiques modernes, s'appuyant notamment sur la vogue de la physiognomonie pour montrer la bonté du pontife.

6 Les chapitres 3 à 5 étudient les formes de l'investissement émotif sur Pie IX. L'auteur met en évidence la grande variété des interprétations de la figure et du rôle du pape, en s'intéressant plus particulièrement aux élites politiques et culturelles italiennes et françaises. Il montre que le mythe de Pie IX eut des conséquences jusqu'au sein de secteurs pourtant peu favorables à l'Église, comme en France certains milieux républicains, révolutionnaires et utopistes. À l'inverse, les contre-révolutionnaires français cachèrent difficilement leur hostilité pour le pape, souvent comparé à Clément XIV, qui avait supprimé la compagnie de Jésus en 1773, et à Louis XVI, dont les réformes avaient débouché sur une révolution. L'auteur étudie par ailleurs les formes d'expression de cet investissement émotif : cris, hymnes, publications et objets divers. Il accorde une importance toute particulière à la prédication, qui, loin d'être alors 
surannée, connut un nouvel âge d'or, illustrant la façon dont l'investissement émotif sur Pie IX mêlait des pratiques anciennes à des mots d'ordre nouveaux.

7 Les deux derniers chapitres étudient les métamorphoses de cet investissement émotif en 1848-1849. L'auteur remet en cause l'idée selon laquelle l'allocution consistoriale du 29 avril, par laquelle Pie IX disait son refus de participer à la guerre contre l'Autriche, aurait mis fin à son image de pape libéral et national. Si le pape refusait de prendre part à une guerre contre un pays catholique, il ne condamnait nullement celle-ci et ne remettait pas en cause ses réformes. De fait, les équivoques perdurèrent encore pendant plusieurs mois et ce ne fut qu'après la fuite de Rome en novembre que le mythe de Pie IX déclina. Par l'allocution consistoriale Quibus quantisque (20 avril 1849), le pontife prenait définitivement ses distances avec son image de pape libéral et national et entamait une dénonciation du monde moderne qui marquerait la suite de son pontificat.

L'épilogue propose une réflexion sur la polysémie des concepts de nation, de liberté et de modernité au milieu du XIX ${ }^{\mathrm{e}}$ siècle, polysémie qui aide largement à comprendre le succès du mythe de Pie IX. Il met notamment en avant l'existence d'une conception proprement catholique de la nation, selon laquelle les peuples régénérés au nom du pape ne l'étaient que parce qu'ils étaient catholiques, c'est-à-dire le produit de la force émancipatrice du christianisme. L'accord entre le catholicisme et la liberté reposait quant à lui sur une conception antirévolutionnaire et anti-individualiste de celle-ci.

Peut-être partiellement contraint par ses sources et par une approche qui tient davantage de l'histoire religieuse et intellectuelle que de l'histoire sociale, l'auteur tend parfois à analyser avant tout le mythe de Pie IX à travers le regard des élites politiques et culturelles. On pourrait regretter qu'une attention plus grande n'ait pas été accordée aux autres couches de la société, d'autant plus que certains passages qui optent pour une telle approche sont particulièrement intéressants (voir les réflexions sur les graffitis inscrits sur les murs romains, p.71-72). La place des femmes dans l'investissement émotif sur Pie IX aurait notamment mérité d'être évoquée, alors même que l'époque est marquée, au moins dans le cas français, par une affirmation du dimorphisme sexuel de la pratique religieuse. L'ouvrage n'en reste pas moins une contribution particulièrement importante à l'histoire du Risorgimento ainsi qu'à celle du catholicisme. 